Supplement of The Cryosphere, 13, 647-663, 2019 https://doi.org/10.5194/tc-13-647-2019-supplement (C) Author(s) 2019. This work is distributed under the Creative Commons Attribution 4.0 License.

(c) (i)

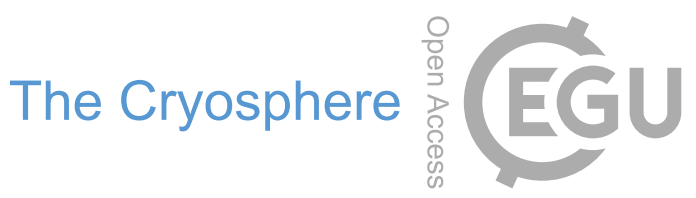

Supplement of

\title{
Large carbon cycle sensitivities to climate across a permafrost thaw gra- dient in subarctic Sweden
}

\author{
K.-Y. Chang et al. \\ Correspondence to: Kuang-Yu Chang (ckychang@lbl.gov)
}

The copyright of individual parts of the supplement might differ from the CC BY 4.0 License. 


\section{Model description}

Ecosys represents multiple canopy and soil layers and fully coupled carbon, energy,

3 water, and nutrient cycles solved at an hourly time step. Surface energy and water exchanges

4 drive soil heat and water transfers to determine soil temperatures and water contents. These

5 transfers drive soil freezing and thawing and, hence, active layer depth, through the general heat

6 flux equation. Carbon uptake is controlled by plant water status calculated from convergence

7 solutions that equilibrate total root water uptake with transpiration. Atmospheric warming

8 increases surface heat advection, soil heat transfers, and hence active layer depth. Canopy

9 temperatures affect $\mathrm{CO}_{2}$ fixation rates from their effects on carboxylation and oxygenation

10 modeled with Arrhenius functions for light and dark reactions. Soil temperatures affect

11 heterotrophic respiration through the same Arrhenius function as for dark reactions.

12 Carbon uptake is also affected by plant nitrogen uptake. The model represents fully

13 coupled transformations of soil carbon, nitrogen, and phosphorus through microbially driven

14 processes. Soil warming enhances carbon uptake by hastening microbial mineralization and root

15 nitrogen uptake. Carbon uptake is affected by phenology with leafout and leafoff (deciduous

16 plants) or dehardening and hardening (evergreen plants) being determined by accumulated

17 exposure to temperatures above set values while day length is increasing or below set values

18 while day length is decreasing. Senescence is driven by excess maintenance respiration and by

19 phenology in deciduous plant functional types.

20

21 Ecosystem-Atmosphere energy exchange:

22 Canopy energy and water exchanges in ecosys are calculated through a multi-layered

23 soil-root-canopy system. The clumping effect for each leaf and stem surface is represented by a 
24 species-specific interception fraction to simulate non-uniformity in the horizontal distribution of

25 leaves within each canopy layer. Coupled first-order closure schemes are solved between the

26 atmosphere and each of leaf and stem surfaces in the multi-layered canopy to achieve energy

27 balance at each model time step. Once the system converges to the required canopy temperature,

28 latent and sensible heat fluxes of each canopy layer are calculated based on the simulated vapor

29 pressure deficit, canopy-atmosphere temperature gradient, aerodynamic conductance, and

30 stomatal conductance. Canopy heat storage is calculated from changes in canopy temperature

31 and heat capacities of leaves, twigs, and stems.

33 Canopy water relations:

34 A convergence solution is sought for the canopy water potential of each plant population 35 at which the difference between its transpiration and total root water uptake equals the difference 36 between its water contents at the previous and current water potentials. Canopy water potential 37 controls transpiration and soil-root water uptake, which affects stomatal conductance and thereby

38 all the processes (e.g., canopy temperature and vapor pressure) described in "Ecosystem-

39 Atmosphere energy exchange". The water table depth in ecosys is calculated at the end of each

40 time step as the depth to the top of the saturated zone below which air-filled porosity is zero.

41 Changes in the simulated water table depth were driven by dynamical interactions among

42 precipitation, evapotranspiration, vertical water transport, and lateral water transport.

43

44 Canopy carbon and nutrient cycling:

45 Leaf carboxylation rates are adjusted from those calculated under non-limiting water 46 potential to those under current water potential. The gross canopy $\mathrm{CO}_{2}$ fixation is the sum of the 
47 leaf carboxylation rate of each leaf surface present on each branch of each plant species, which is

48 then transported to a mobile pool of carbon storage. Storage carbon oxidized in excess of

49 maintenance respiration requirements is used as growth respiration to drive the formation of new

50 biomass. $\mathrm{Net}^{\mathrm{CO}_{2}}$ fixation is calculated as the difference between gross fixation and the sum of

51 maintenance, growth, and senescence respiration in the simulated canopy.

$52 \quad$ Nutrient (nitrogen and phosphorous) uptake is calculated for each plant species by

53 solving for aqueous concentrations at root and mycorrhizal surfaces in each soil layer at which

54 radial transport by mass flow and diffusion from the soil solution to the surfaces equals active

55 uptake by the surfaces. This solution dynamically links rates of soil nutrient transformations with

56 those of root and mycorrhizal nutrient uptake. The products of nitrogen and phosphorous uptake

57 are transported to mobile pools of nitrogen and phosphorous stored in each root and mycorrhizal

58 layer, which regulate vegetation growth.

60 Plant functional type dynamics:

61 The model represents prognostic vegetation dynamics with internal resource allocation

62 and remobilization. Shifts in plant functional types are modeled through processes of plant

63 functional type competition for light, water, and nutrients within each canopy and rooted soil

64 layer depending on leaf area and root length. Each plant functional type competes for nutrient

65 and water uptake from common nutrient and water stocks held across multi-layer soil profiles,

66 calculated from algorithms for transformations and transfers of soil carbon, nitrogen, and

67 phosphorus, and for transfers of soil water. Modeled differences in plant functional type

68 functional traits determine the strategy of resource acquisition and allocation that drive growth, 
69 resource remobilization, and litterfall, and therefore each plant functional type dynamic

70 competitive capacity under different environmental conditions.

71

72 Soil microbial activity:

73 The modeling of microbial activity is based on six organic states: solid, soluble, sorbed,

74 acetate, microbial biomass, and microbial residues. Carbon, nitrogen and phosphorous may move

75 among these states within each of four organic matter-microbe complexes: plant litterfall, animal

76 manure, particulate organic matter, and humus. Microbial biomass in ecosys is an active agent of

77 organic matter transformation. The rate at which each component is hydrolyzed is a function of

78 substrate concentration that approaches a first-order function at low concentrations, and a zero-

79 order function at high concentrations. These rates are regulated by soil temperature through an

80 Arrhenius function and by soil water content through its effect on microbial concentration.

81 Similar to the growth and decline of vegetation biomass described above, the net change in

82 microbial biomass is determined by the difference between heterotrophic respiration and

83 maintenance respiration. When heterotrophic respiration is greater than maintenance respiration,

84 the excessive amount of respiration is used as growth respiration that drives microbial growth

85 according to the energy requirements of biosynthesis. 
87 Supplemental Material Table 1. Key soil properties of the (a) palsa (b) bog (c) fen at the 88 Stordalen Mire used in ecosys.

\begin{tabular}{ccccccccc} 
& $\begin{array}{c}\text { Depth } \\
\mathrm{m}\end{array}$ & $\begin{array}{c}\mathrm{BD} \\
\mathrm{mg} \mathrm{m}^{-3}\end{array}$ & $\begin{array}{c}\mathrm{K}_{\mathrm{sat}} \\
\mathrm{mm} \mathrm{h}^{-1}\end{array}$ & $\begin{array}{c}\mathrm{TOC} \\
\mathrm{g} \mathrm{kg}^{-1}\end{array}$ & $\begin{array}{c}\mathrm{TON} \\
\mathrm{g} \mathrm{kg}^{-1}\end{array}$ & $\begin{array}{c}\mathrm{FC} \\
\mathrm{m}^{3} \mathrm{~m}^{-3}\end{array}$ & $\begin{array}{c}\text { WP } \\
\mathrm{m}^{3} \mathrm{~m}^{-3}\end{array}$ & $\mathrm{pH}$ \\
\hline (a) Palsa & & & & & & & & \\
& 0.01 & 0.10 & 100 & 452.04 & 8.88 & 0.4 & 0.15 & 3.9 \\
& 0.05 & 0.10 & 100 & 438.38 & 9.62 & 0.4 & 0.15 & 3.9 \\
0.1 & 0.12 & 25 & 388.16 & 10.90 & 0.4 & 0.15 & 3.9 \\
0.2 & 0.20 & 25 & 343.97 & 12.21 & 0.4 & 0.15 & 3.9 \\
0.3 & 0.30 & 25 & 331.83 & 13.86 & 0.4 & 0.15 & 4.1 \\
0.4 & 0.80 & 20 & 304.80 & 14.19 & 0.4 & 0.15 & 4.5 \\
0.5 & 1.20 & 18 & 208.73 & 10.89 & 0.4 & 0.15 & 4.4 \\
0.6 & 1.20 & 15 & 206.77 & 10.88 & 0.4 & 0.15 & 4.4 \\
0.7 & 1.23 & 13 & 203.92 & 10.77 & 0.4 & 0.15 & 5.1 \\
0.9 & 1.25 & 12 & 200.71 & 11.10 & 0.4 & 0.15 & 5.3 \\
1.1 & 1.25 & 12 & 150.00 & 8.60 & 0.2 & 0.11 & 5.3 \\
1.3 & 1.35 & 10 & 120.00 & 7.60 & 0.2 & 0.11 & 5.3 \\
1.5 & 1.35 & 10 & 120.00 & 7.60 & 0.2 & 0.11 & 5.3
\end{tabular}

(b) Bog

$\begin{array}{cccccccc}0.01 & 0.02 & 500 & 390.20 & 4.22 & 0.4 & 0.15 & 4.2 \\ 0.05 & 0.02 & 500 & 407.15 & 5.59 & 0.4 & 0.15 & 4.2 \\ 0.1 & 0.04 & 500 & 403.20 & 6.81 & 0.4 & 0.15 & 4.2 \\ 0.2 & 0.04 & 500 & 418.90 & 8.83 & 0.4 & 0.15 & 4.2 \\ 0.3 & 0.15 & 300 & 461.90 & 11.93 & 0.4 & 0.15 & 4.2 \\ 0.4 & 0.35 & 200 & 466.60 & 13.06 & 0.4 & 0.15 & 4.4 \\ 0.5 & 1.05 & 100 & 466.20 & 13.30 & 0.4 & 0.15 & 4.6 \\ 0.6 & 1.25 & 60 & 406.20 & 13.30 & 0.4 & 0.15 & 4.7 \\ 0.7 & 1.30 & 50 & 406.20 & 13.30 & 0.4 & 0.15 & 4.8 \\ 0.9 & 1.33 & 40 & 406.20 & 13.30 & 0.4 & 0.15 & 4.9 \\ 1.1 & 1.35 & 25 & 400.00 & 13.60 & 0.2 & 0.11 & 5.0 \\ 1.3 & 1.35 & 15 & 400.00 & 13.60 & 0.2 & 0.11 & 5.0 \\ 1.5 & 1.35 & 15 & 400.00 & 13.60 & 0.2 & 0.11 & 5.0\end{array}$

(c) Fen

$\begin{array}{cccccccc}0.01 & 0.02 & 500 & 436.90 & 13.47 & 0.4 & 0.15 & 5.7 \\ 0.05 & 0.02 & 500 & 435.18 & 14.97 & 0.4 & 0.15 & 5.7 \\ 0.1 & 0.04 & 500 & 435.14 & 15.55 & 0.4 & 0.15 & 5.7 \\ 0.2 & 0.04 & 500 & 380.83 & 15.55 & 0.4 & 0.15 & 5.7 \\ 0.3 & 0.15 & 300 & 340.83 & 14.47 & 0.4 & 0.15 & 5.7 \\ 0.4 & 0.35 & 200 & 336.51 & 16.49 & 0.4 & 0.15 & 5.7 \\ 0.5 & 0.70 & 100 & 336.51 & 17.65 & 0.4 & 0.15 & 5.7\end{array}$


$\begin{array}{llllllll}0.6 & 1.10 & 60 & 430.21 & 22.65 & 0.4 & 0.15 & 5.7\end{array}$

$\begin{array}{llllllll}0.7 & 1.20 & 50 & 430.21 & 22.65 & 0.4 & 0.15 & 5.8\end{array}$

$\begin{array}{llllllll}0.9 & 1.25 & 40 & 430.51 & 22.65 & 0.4 & 0.15 & 5.9\end{array}$

$\begin{array}{llllllll}1.1 & 1.30 & 25 & 430.51 & 22.60 & 0.2 & 0.11 & 6.0\end{array}$

$\begin{array}{llllllll}1.3 & 1.35 & 15 & 380.00 & 20.60 & 0.2 & 0.11 & 6.0\end{array}$

$\begin{array}{llllllll}1.5 & 1.35 & 15 & 380.00 & 20.60 & 0.2 & 0.11 & 6.0\end{array}$

89 Abbreviations BD: bulk density, $\mathrm{K}_{\text {sat }}$ : saturated hydraulic conductivity, TOC: total organic

90 carbon, TON: total organic nitrogen, FC: field capacity, WP: wilting point.

91 
92 Supplemental Material Table 2. Key vegetation parameters of the (a) palsa (b) bog (c) fen at the

93 Stordalen Mire used in ecosys.

Palsa

$\begin{array}{cccccccc}\mathrm{V}_{\mathrm{c}, \max } & \mathrm{C}_{\mathrm{i}}: \mathrm{C}_{\mathrm{a}} & \mathrm{SLA} & \text { Leaf N:C } & \text { Root N:C } & \text { Leaf P:C } & \text { Root P:C } & \begin{array}{c}\text { Planting } \\ \text { density }\end{array} \\ \mu \mathrm{mol} \mathrm{g}^{-1} \mathrm{~s}^{-1} & & \mathrm{~m}^{2} / \mathrm{g} \mathrm{C} & \mathrm{g} \mathrm{N} / \mathrm{g} \mathrm{C} & \mathrm{g} \mathrm{N} / \mathrm{g} \mathrm{C} & \mathrm{g} \mathrm{P} / \mathrm{g} \mathrm{C} & \mathrm{g} \mathrm{P} / \mathrm{g} \mathrm{C}^{-2} & \mathrm{~m}^{-2}\end{array}$

(a)

$\begin{array}{lcccccccccc}\text { Palsa } & & & & & & \\ & \text { Shrub } & 45 & 0.7 & 4.50 \mathrm{E}-03 & 7.00 \mathrm{E}-02 & 1.75 \mathrm{E}-02 & 7.00 \mathrm{E}-03 & 1.75 \mathrm{E}-03 & 1.00 \mathrm{E}+00 \\ & \text { Lichen } & 45 & 0.7 & 1.67 \mathrm{E}-03 & 4.00 \mathrm{E}-02 & 2.00 \mathrm{E}-02 & 4.00 \mathrm{E}-03 & 2.00 \mathrm{E}-03 & 1.00 \mathrm{E}+02 \\ & \text { Moss } & 45 & 0.7 & 1.67 \mathrm{E}-03 & 8.00 \mathrm{E}-02 & 4.00 \mathrm{E}-02 & 8.00 \mathrm{E}-03 & 4.00 \mathrm{E}-03 & 1.00 \mathrm{E}+03 \\ & \text { Sedge } & 45 & 0.7 & 3.33 \mathrm{E}-03 & 1.00 \mathrm{E}-01 & 2.50 \mathrm{E}-02 & 1.00 \mathrm{E}-02 & 2.50 \mathrm{E}-03 & 1.00 \mathrm{E}+00 \\ \text { (b) } & & & & & & & & & \\ \text { Bog } & & & & & & & & & \\ & \text { Moss } & 45 & 0.7 & 1.67 \mathrm{E}-03 & 4.00 \mathrm{E}-02 & 2.00 \mathrm{E}-02 & 4.00 \mathrm{E}-03 & 2.00 \mathrm{E}-03 & 6.00 \mathrm{E}+03 \\ & \text { Sedge } & 45 & 0.7 & 3.33 \mathrm{E}-03 & 1.00 \mathrm{E}-01 & 2.50 \mathrm{E}-02 & 1.00 \mathrm{E}-02 & 2.50 \mathrm{E}-03 & 2.00 \mathrm{E}+01 \\ \text { (c) } & & & & & & & & & \\ \text { Fen } & & & & & & & & & & \end{array}$

94

95 Abbreviations Vc, max: Rubisco Carboxylation Activity, Ci:Ca: Ratio of CO2 concentration

96 across stomata, SLA: Specific Leaf Area, Leaf N:C: Leaf Nitrogen:Carbon ratio, Root N:C: Root

97 Nitrogen:Carbon ratio, Leaf P:C: Leaf Phosphorus:Carbon ratio, Root P:C: Root

98 Phosphorus:Carbon ratio

99 

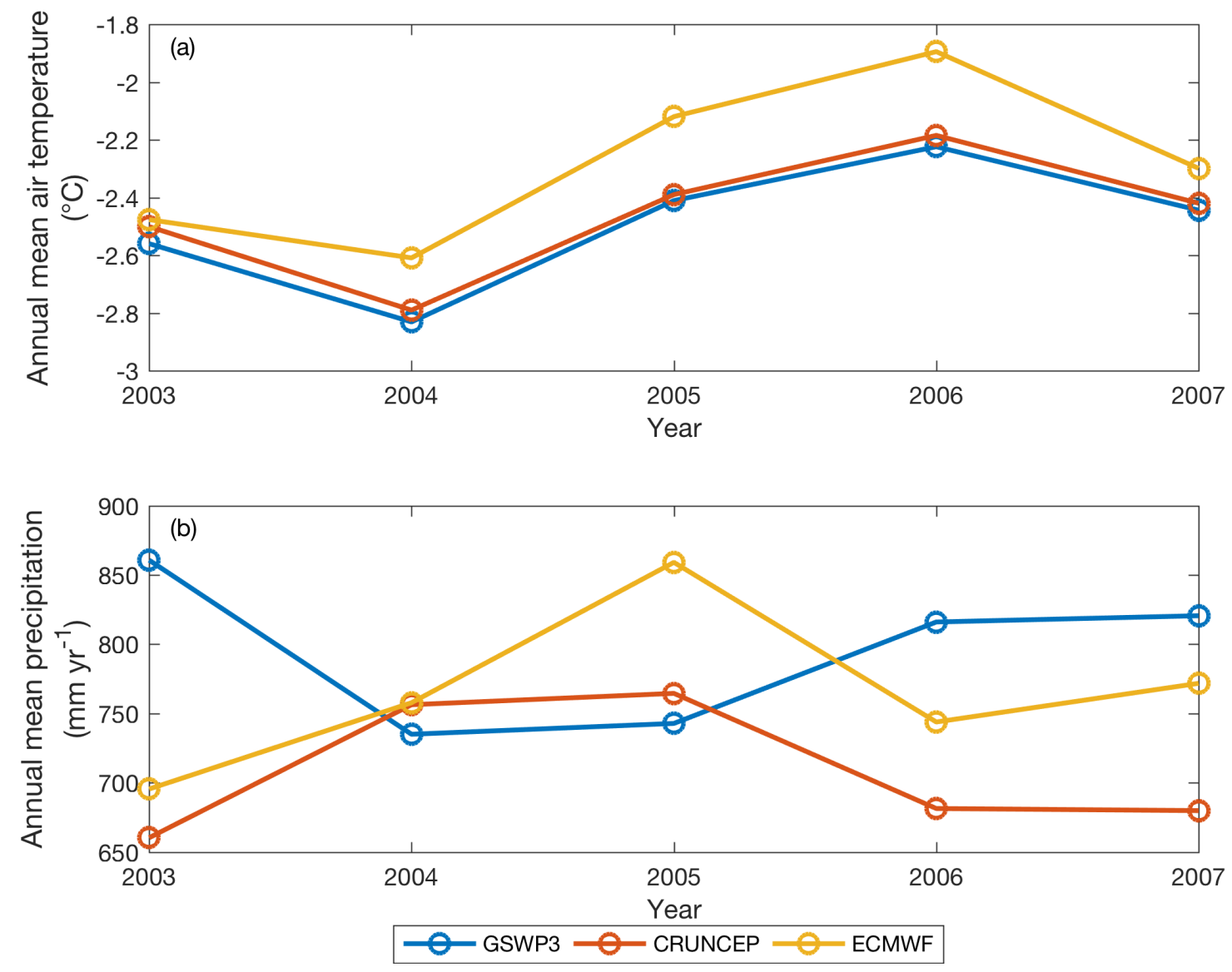

101 Supplemental Material Figure 1. Annual mean air temperature (a) and precipitation (b) extracted 102 from GSWP3 (blue), CRUNCEP (red), and ECMWF (yellow) at the Stordalen Mire. 